\title{
EFFECT OF COPPER SULPHATE PENTAHYDRATE ON MOSQUITO LARVAL AEDES AEGYPTI, CULEX QUINQUEFASCIATUS, AND ANOPHELES QUADRIMACULATUS IN LABORATORY AND UNDER SEMI-FIELD CONDITIONS
}

\author{
MD ASADUZZAMAN MIAH ${ }^{1,2}$ KAI BLORE', AND RUI-DE XUE $^{1}$ \\ 'Anastasia Mosquito Control District, 120 EOC Drive, \\ St. Augustine, Florida 32092, USA
}

${ }^{2}$ Patuakhali Science and Technology University, Bangladesh

Email: xueamcd@gmail.com; mamiah81@yahoo.com

Guest Editor: Vindhya S. Aryaprema

\begin{abstract}
Mosquito larval control has been conducted by various chemicals and biological agents to reduce mosquito population and mosquito-borne diseases. The larvicidal efficacy of Copper sulphate pentahydrate $\left(\mathrm{CuSO}_{4} \cdot 5 \mathrm{H}_{2} \mathrm{O}\right)$ on $\mathrm{Aedes}$ aegypti, Culex quinquefasciatus and Anopheles quadrimaculatus was evaluated separately in the laboratory and semi-field conditions. Different concentrations of $\mathrm{CuSO}_{4} \cdot 5 \mathrm{H}_{2} \mathrm{O}$ (ranging from 1 to $20 \mathrm{ppm}$ ) were tested against third ( $3^{\text {rd }}$ ) instar larvae. Larval mortality was observed at $24,48 \& 72 \mathrm{~h}$ after exposure and the $\mathrm{LC}_{50}$ values were determined. In both conditions, larval mortality showed concentration and time dependent correlations i.e. larval mortality was higher with increasing concentration $\mathrm{CuSO}_{4} \cdot 5 \mathrm{H}_{2} \mathrm{O}$ and exposure time. No mortality was observed in the control $(0 \mathrm{ppm})$. Of the three species tested, Cx. quinquefasciatus and An. quadrimaculatus were more sensitive to $\mathrm{CuSO}_{4} \cdot 5 \mathrm{H}_{2} \mathrm{O}$ than $A e$. aegypti. It was demonstrated that $1.5-2.25 \mathrm{ppm}$ of $\mathrm{CuSO}_{4} \cdot 5 \mathrm{H}_{2} \mathrm{O}$ killed more than $50 \%$ of $C x$. quinquefasciatus and An. quadrimaculatus larvae at $72 \mathrm{~h}$ in both laboratory and semi-field conditions, whereas Ae. aegypti could survive easily in these concentrations. Besides, $\mathrm{CuSO}_{4} \cdot 5 \mathrm{H}_{2} \mathrm{O}$ showed more toxicity to larvae in semi-field conditions than laboratory studies. These results suggest that $\mathrm{CuSO}_{4} \cdot 5 \mathrm{H}_{2} \mathrm{O}$ could be used as a potential larvicide especially for Cx. quinquefasciatus and An. quadrimaculatus as a low-cost alternative larvicidal agent. Further studies will be needed to confirm its effectiveness in large scale field trials.
\end{abstract}

Key Words: Copper sulphate pentahydrate $\left(\mathrm{CuSO}_{4} \cdot 5 \mathrm{H}_{2} \mathrm{O}\right)$, Ae. aegypti, An. quadrimaculatus, Cx. quinquefasciatus, larvicide

\section{INTRODUCTION}

Mosquitoes are one of the deadliest organisms in the world and a serious threat to public health. Mosquito-borne diseases are prevalent in more than 100 countries across the world that causes millions of deaths every year (WHO, 2009). More than half of the world's population live in the areas with a risk of mosquito-borne diseases. Diseases such as dengue, chikungunya, yellow fever, Zika, malaria, filariasis, Japanese encephalitis, West Nile fever, etc. are transmitted among humans mainly by three genera of mosquitoes, Aedes, Anopheles and Culex (Remia and Logaswamy, 2010; Arivoli et al.,
2011). Therefore, mosquitoes and mosquito-borne diseases have become challenging problems that have social and economic impacts (Raveen et al., 2014).

Adult and larval mosquito control have been undertaken by many vector control programs to suppress mosquito-borne diseases in many countries. Larval control has been assumed as the main strategy for successful mosquito control programs. Chemical insecticides are commonly considered to be the most effective control strategy against mosquitoes. However, concern has increased significantly regarding their negative effects, such as the development of resistance in mosquitoes, toxicity to non- 
target organisms, potential health hazards, water contamination, environmental pollution, and residual effects (Ndakidemi et al., 2016). In recent years, Bacillus thuringiensis israelensis (Bti) and insect growth regulators (IGRs) have been used widely to control mosquito larvae. These are comparatively expensive, and they have some limitations too. Scientists, therefore, have been looking for alternatives for managing the mosquito larvae. Accordingly, we attempted in this study to utilize Copper sulphate pentahydrate $\left(\mathrm{CuSO}_{4} \cdot 5 \mathrm{H}_{2} \mathrm{O}\right)$ solution as a mosquito larvicide because it is a cheap alternative to Bti and IGRs. $\mathrm{CuSO}_{4} \cdot 5 \mathrm{H}_{2} \mathrm{O}$ is easily obtained and maintained, and has bactericidal, algicidal and fungicidal effects, which is beneficial for bacterial, algal or fungal contamination (Biagi et al., 2014).

Copper sulphate pentahydrate $\left(\mathrm{CuSO}_{4}\right.$. $\left.5 \mathrm{H}_{2} \mathrm{O}\right)$, commercially formulated as REXCU-S (DNW Global, USA), has been used for the suppression of bacterial odors and toxic gas in standing or moving water bodies containing organic matter of algae or bacteria. It is used worldwide as an algaecide and a fungicide in aquaculture and agriculture (Lasiene et al., 2016). Elevated levels of copper in water is long known to adversely affect survival, growth, reproduction, feeding and even cause morphological deformity on aquatic organisms (Hodson et al., 1979). It is also used as a therapeutic chemical for various ectoparasitic and bacterial infections. The toxic effect of $\mathrm{CuSO}_{4} \cdot 5 \mathrm{H}_{2} \mathrm{O}$ was examined in freshwater fish, Capoeta umbla (Kirici et al., 2017). The acute and chronic toxicity of copper to aquatic midge like Chironomus ramosus (Majumdar and Gupta 2012), Chironomus tentans (Nebeker et. al., 1984 and Warrin et. al., 2009) and Chironomus decorus (Kosalwat and Knight 1987) was studied previously to determine the $\mathrm{LC}_{50}$ values. The ability of copper to kill or injure mosquito larvae was studied by Reza et al. (2012). Their study revealed that copper, in both its solid and liquid forms, was lethal to mosquito larvae at a concentration of 1.2 ppm (Reza et al., 2012). Furthermore, in another study in 2014, they demonstrated that $10 \mathrm{ppm}$ of copper solution could kill more than $90 \%$ larvae of An. stephensi, Ae. albopictus and Cx. pipiens pallens at 96 hours exposure (Reza et al., 2014). These results encouraged us to evaluate $\mathrm{CuSO}_{4} \cdot 5 \mathrm{H}_{2} \mathrm{O}$ solution as a mosquito larvicide.

The present study investigated the larvicidal potential of $\mathrm{CuSO}_{4} \cdot 5 \mathrm{H}_{2} \mathrm{O}$ against $3^{\text {rd }}$ instar larvae of Ae. aegypti, An. quadrimaculatus, and $C x$. quinquefasciatus under laboratory and semi-field conditions.

\section{MATERIALS AND METHODS}

Mosquito larvae. Three species of mosquitoes Ae. aegypti, An. quadrimaculatus and $C x$. quinquefasciatus were maintained at the insectary, Anastasia Mosquito Control District (AMCD), Florida, USA. The eggs of mosquitoes (target species) were hatched and kept in water up to $3^{\text {rd }}$ instar larvae. The third $\left(3^{\text {rd }}\right)$ instar larvae of each species were collected from the insectary and used in this study to conduct trials in the laboratory and semi field conditions.

Larvicide. A commercial solution of $\mathrm{CuSO}_{4} \cdot 5 \mathrm{H}_{2} \mathrm{O}$ (REXCU-S) [(19.8 \% active ingredient-a.i. and $80.2 \%$ other ingredients), a soluble liquid blue in color] was purchased from DNW Global LLC, Florida, USA. For larval bioassay, the concentrations (ppm) were prepared on the a.i. of $\mathrm{CuSO}_{4} \cdot 5 \mathrm{H}_{2} \mathrm{O}$.

Larval bioassays. Bioassays were carried out separately in the laboratory and semifield conditions for all species of mosquito larvae. The $3^{\text {rd }}$ instar larvae were visually detected using size as the determinant. Larvicidal activity (percentage of mortality) and $\mathrm{LC}_{50}$ values were calculated using the WHO (2005) bioassay protocol with slight modifications. The tested larvae were free from any exposure to insecticides or chemicals.

In the laboratory conditions, seven (7) different concentrations $(1,2,6,10,14,18$, and $20 \mathrm{ppm}$ ) of $\mathrm{CuSO}_{4} \cdot 5 \mathrm{H}_{2} \mathrm{O}$ (a.i.) were prepared from the stock solution using distilled water (stock solution is made just before experimentation). Ten larvae of each species were released by means of a dropper into a $250 \mathrm{~mL}$ transparent plastic cup containing $100 \mathrm{~mL}$ of each concentration of the solution. A control (distilled water only) was also included with each concentration. For each 
concentration, four (4) replicates were conducted to check the mortality in a completely randomized design (CRD). All the experimental cups were placed on a tray and kept it in the incubator at $26(2 \pm){ }^{\circ} \mathrm{C}$ under $12: 12$ light: dark regime with $80 \%$ relative humidity. No food was provided for larvae during this experimentation.

In the semi-field conditions, five (5) different concentrations $(2,5,10,15$ and 20 ppm) of $\mathrm{CuSO}_{4} \cdot 5 \mathrm{H}_{2} \mathrm{O}$ (a.i.) were prepared from the stock solution using distilled water. For Ae. aegypti, twenty-five (25) larvae were released by means of a dropper into a $20 \mathrm{~L}$ black plastic bucket containing $9 \mathrm{~L}$ of each concentration of the solution. A control (distilled water only) was also included with each concentration. For each concentration, four (4) replicates were conducted to check the mortality in a CRD. All the experimental buckets were kept in the AMCD field (location: $29^{\circ} 54^{\prime} 09.0^{\prime \prime} \mathrm{N} 81^{\circ} 24^{\prime} 46.4^{\prime \prime} \mathrm{W}$ ) under natural environment. No food was provided for larvae during this experimentation. For An. quadrimaculatus and Cx. quinquefasciatus, two hundred (200) larvae were released by means of a dropper into a 950 L cement tank containing $750 \mathrm{~L}$ of each concentration of the solution made with well water. A control (well water only) tank was also maintained for each concentration. Four (4) replicates were conducted for each concentration to check the mortality. All the experimental tanks were in the AMCD field (location: $29^{\circ} 54^{\prime} 08.4^{\prime \prime} \mathrm{N} 81^{\circ} 24^{\prime} 47.1^{\prime \prime} \mathrm{W}$ ) under natural environment. A little food (2 grams fish food) was provided for larvae during the experimentation.

Larval mortality for each condition were determined by counting the number of dead larvae. Larvae were considered dead if they showed no sign of movement even after being touched with a glass rod (Langat et al., 2012). The percentage of larval mortality was recorded after 24,48 , and $72 \mathrm{~h}$ and corrected using Abbott's formula (Abbott, 1925):

\footnotetext{
$\%$ mortality in treated

Corrected mortality $(\%)=\frac{-\% \text { mortality in control }}{100-\% \text { mortality in }} \wedge 100$ control
}

Statistical analysis. Statistical analysis of the experimental data was performed with "MS EXCEL 2010 program" and GraphPad Prism 5.0 (GraphPad Software, Inc., San Diego, CA) to find out mortality percentage, regression equations (y), and correlation $\mathrm{co}^{-}$ efficient values $(\mathrm{r})$. The $\mathrm{LC}_{50}$ values were estimated using Probit analysis (Finney, 1971).

\section{RESULTS}

\section{Effect of $\mathrm{CuSO}_{4} \cdot 5 \mathrm{H}_{2} \mathrm{O}$ in Laboratory condi- tions.}

The percentages of larval mortality at 24, 48 , and $72 \mathrm{~h}$ after exposure to the seven (7) different concentrations of the $\mathrm{CuSO}_{4} \cdot 5 \mathrm{H}_{2} \mathrm{O}$ solution are presented in Table 1. Mortalities increased with an increase in the concentration (ppm) of $\mathrm{CuSO}_{4} \cdot 5 \mathrm{H}_{2} \mathrm{O}$ solution for all species at any time period of exposure during experiment. At $72 \mathrm{~h}$ exposure time, the highest mortality (97.5 to $100 \%)$ was observed for all species. The correlation analysis showed that mortality and concentration was positively correlated ( $r$ ) for all species (Fig. 1).

The $\mathrm{LC}_{50}$ values of $\mathrm{CuSO}_{4} \cdot 5 \mathrm{H}_{2} \mathrm{O}$ solution at 24,48 , and $72 \mathrm{~h}$ after exposure against the $3^{\text {rd }}$ instar larvae of Ae. aegypti, An. quadrimaculatus, and $C x$. quinquefasciatus were determined (Table 3). The LC $_{50}$ values decreased with the increase of larval exposure time. The $\mathrm{CuSO}_{4} \cdot 5 \mathrm{H}_{2} \mathrm{O}$ solution exhibited the highest larvicidal activity at $72 \mathrm{~h}$ after exposure against Ae. aegypti, An. quadrimaculatus, and $C x$. quinquefasciatus larvae with their lowest $\mathrm{LC}_{50}$ values of 5.5, 2.25 and 2 ppm, respectively.

\section{Effect of $\mathrm{CuSO}_{4} \cdot 5 \mathrm{H}_{2} \mathrm{O}$ in Semi-field condi- tions.}

The percent larval mortality at 24, 48, and $72 \mathrm{~h}$ after exposure to the five (5) different concentrations of the $\mathrm{CuSO}_{4} \cdot 5 \mathrm{H}_{2} \mathrm{O}$ solution are presented in Table 2. Mortalities increased with the increase of the concentration of the $\mathrm{CuSO}_{4} \cdot 5 \mathrm{H}_{2} \mathrm{O}$ solution for all species at any time period of exposure. At $48 \mathrm{~h}$ exposure time, the highest mortality $(100 \%)$ was observed for all species. The correlation 
Table 1. Larval mortality (\%) of Aedes aegypti, Anopheles quadrimaculatus, and Culex quinquefasciatus at 24, 48, and 72 $\mathrm{h}$ after exposure to CuSO $4 \cdot 5 \mathrm{H} 2 \mathrm{O}$ solution (REXCU-S) in laboratory conditions.

\begin{tabular}{|c|c|c|c|c|}
\hline \multirow[b]{2}{*}{ Mosquito species } & \multirow[b]{2}{*}{ Concentration (ppm) } & \multicolumn{3}{|c|}{$\%$ Mortality (Mean) } \\
\hline & & $24 \mathrm{~h}$ & $48 \mathrm{~h}$ & $72 \mathrm{~h}$ \\
\hline \multirow[t]{8}{*}{ Ae. aegypti } & 0 (Control) & 0 & 0 & 0 \\
\hline & 1 & 0 & 5 & 5 \\
\hline & 2 & 5 & 10 & 17.5 \\
\hline & 6 & 12.5 & 45 & 57.5 \\
\hline & 10 & 30 & 57.5 & 65 \\
\hline & 14 & 52.5 & 82.5 & 82.5 \\
\hline & 18 & 77.5 & 92.5 & 95 \\
\hline & 20 & 87.5 & 97.5 & 97.5 \\
\hline \multirow[t]{8}{*}{ An. quadrimaculatus } & 0 (Control) & 0 & 3 & 4 \\
\hline & 1 & 7.5 & 20 & 35 \\
\hline & 2 & 10 & 25 & 50 \\
\hline & 6 & 25 & 37.5 & 87.5 \\
\hline & 10 & 42.5 & 62.5 & 82.5 \\
\hline & 14 & 67.5 & 82.5 & 92.5 \\
\hline & 18 & 77.5 & 80 & 97.5 \\
\hline & 20 & 92.5 & 92.5 & 100 \\
\hline \multirow[t]{8}{*}{ Cx. quinquefasciatus } & 0 (Control) & 0 & 0 & 0 \\
\hline & 1 & 0 & 5 & 42.5 \\
\hline & 2 & 7.5 & 17.5 & 57.5 \\
\hline & 6 & 25 & 42.5 & 95 \\
\hline & 10 & 25 & 67.5 & 95 \\
\hline & 14 & 42.5 & 95 & 100 \\
\hline & 18 & 75 & 92.5 & 97.5 \\
\hline & 20 & 75 & 95 & 100 \\
\hline
\end{tabular}

analysis showed that mortality and concentration is positively correlated $(r)$ for all species (Fig. 1). This gradient of positive dependency between mortality and concentration is the key and common characteristic of any functional larvicide.

The $\mathrm{LC}_{50}$ values of the $\mathrm{CuSO}_{4} \cdot 5 \mathrm{H}_{2} \mathrm{O}$ solution at 24, 48, and $72 \mathrm{~h}$ after exposure against the larvae of Ae. aegypti, An. quadrimaculatus, and Cx. quinquefasciatus were determined (Table 3). The $\mathrm{LC}_{50}$ values decreased with the increase of larval exposure time. The $\mathrm{CuSO}_{4} \cdot 5 \mathrm{H}_{2} \mathrm{O}$ solution exhibited the highest larvicidal activity at $72 \mathrm{~h}$ after exposure against Ae. aegypti, An. quadrimaculatus, and Cx. quinquefasciatus larvae with the lowest $\mathrm{LC}_{50}$ values of $3,1.5$ and $1.5 \mathrm{ppm}$, respectively.

Significant differences were observed in the efficacy of the $\mathrm{CuSO}_{4} \cdot 5 \mathrm{H}_{2} \mathrm{O}$ solution to kill larvae when evaluated in the laboratory and semi-field conditions. The $\mathrm{LC}_{50}$ values of $\mathrm{CuSO}_{4} \cdot 5 \mathrm{H}_{2} \mathrm{O}$ against the larvae of $A e . a e-$ gypti, An. quadrimaculatus, and Cx. quinquefasciatus were comparatively low in semi-field conditions compared to laboratory assays. Altogether, in this study, the $\mathrm{CuSO}_{4} \cdot 5 \mathrm{H}_{2} \mathrm{O}$ solution was observed with higher toxicity to Cx. quinquefasciatus and An. quadrimaculatus than to Ae. aegypti in both laboratory and semi-field studies.

\section{DISCUSSION}

The $\mathrm{CuSO}_{4} \cdot 5 \mathrm{H}_{2} \mathrm{O}$ solution exhibited prominent larvicidal activity at different concentrations against $3^{\text {rd }}$ instar larvae of Ae. aegypti, An. quadrimaculatus and Cx. quinquefasciatus during laboratory and semi-field studies.

This gradient of positive dependency between mortality and concentration revealed that $\mathrm{CuSO}_{4} \cdot 5 \mathrm{H}_{2} \mathrm{O}$ could be a rational larvicide for mosquitoes. The high mortality rate 
Dose-response curve (72 h)
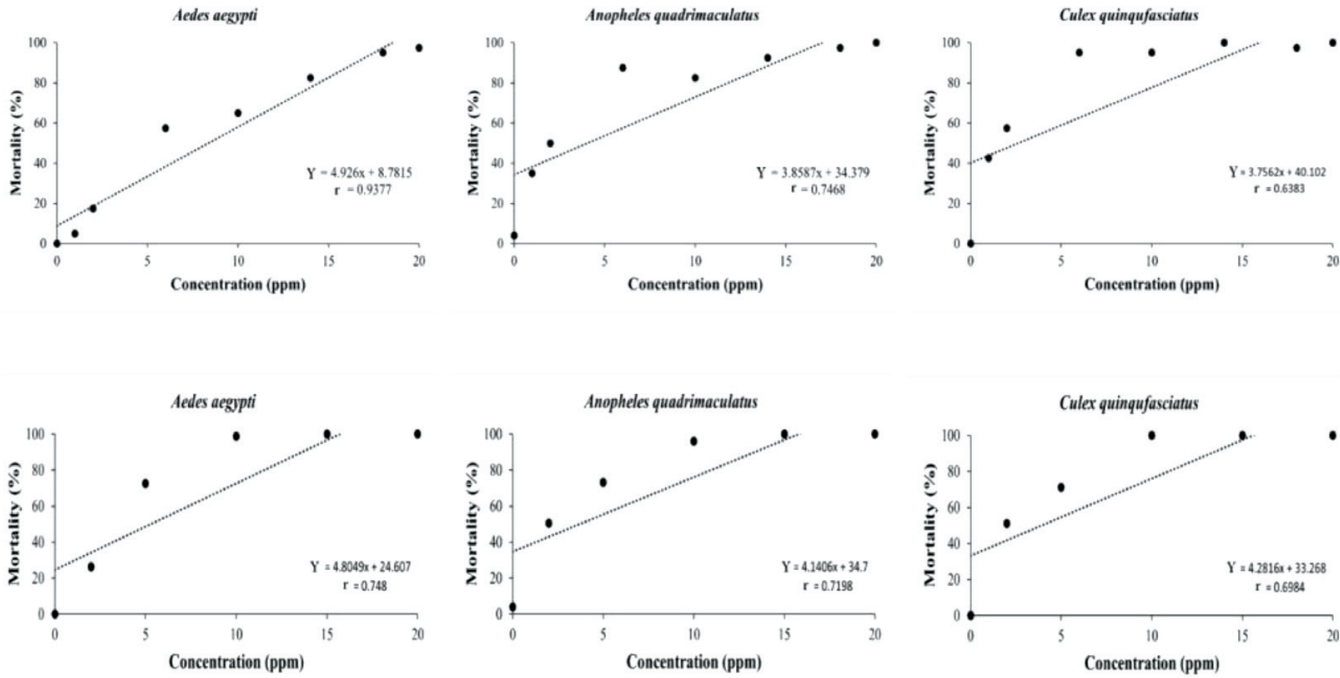

Figure 1. Dose-response curve (Linear regression equation $(\mathrm{Y})$ and correlation coefficient (r) between $\mathrm{CuSO} 4 \cdot 5 \mathrm{H} 2 \mathrm{O}$ concentration and larval mortality at $72 \mathrm{~h}$ after exposure). The mortality percentage increased with increasing concentrations showed a positive correlation.

(upper panel: lab condition; lower panel: semi-field condition)

may have been due to the large number of copper molecules that bound with receptors in the larval midgut, because copper was previously shown to damage the peritrophic matrix in the midgut (Beaty et al., 2002). In contrast, it is speculated that larval exposure to $\mathrm{CuSO}_{4} \cdot 5 \mathrm{H}_{2} \mathrm{O}$ solution for a short period of time at a lower concentration resulted in a lower mortality rate because of a reduction in copper ions binding with the receptors in

Table 2. Larval mortality (\%) of Aedes aegypti, Anpheles quadrimaculatus, and Culex quinquefasicatus at 24, 48, and 72 $\mathrm{h}$ after exposure to CuSO $4.5 \mathrm{H} 2 \mathrm{O}$ solution (REXCU-S) in semi-field conditions

\begin{tabular}{|c|c|c|c|c|}
\hline \multirow[b]{2}{*}{ Mosquito species } & \multirow[b]{2}{*}{ Concentration (ppm) } & \multicolumn{3}{|c|}{$\%$ Mortality (Mean) } \\
\hline & & $24 \mathrm{~h}$ & $48 \mathrm{~h}$ & $72 \mathrm{~h}$ \\
\hline \multirow[t]{6}{*}{ Ae. aegypti } & 0 (Control) & 0 & 0 & 0 \\
\hline & 2 & 7.5 & 20 & 26.25 \\
\hline & 5 & 41.25 & 66.25 & 72.5 \\
\hline & 10 & 88.75 & 97.5 & 98.75 \\
\hline & 15 & 96.25 & 100 & 100 \\
\hline & 20 & 97.5 & 100 & 100 \\
\hline \multirow[t]{6}{*}{ An. quadrimaculatus } & 0 (Control) & 1.5 & 3 & 4 \\
\hline & 2 & 9.38 & 15 & 50.38 \\
\hline & 5 & 24.88 & 31.75 & 73.13 \\
\hline & 10 & 78.75 & 86 & 96 \\
\hline & 15 & 94.38 & 100 & 100 \\
\hline & 20 & 100 & 100 & 100 \\
\hline \multirow[t]{6}{*}{ Cx. quinquefasciatus } & 0 (Control) & 0 & 0 & 0 \\
\hline & 2 & 3.38 & 18.50 & 51 \\
\hline & 5 & 67.63 & 76.38 & 71.25 \\
\hline & 10 & 86 & 100 & 100 \\
\hline & 15 & 90 & 100 & 100 \\
\hline & 20 & 95.38 & 100 & 100 \\
\hline
\end{tabular}


Table 3. Probit analysis of the larvicidal efficacy of CuSO4.5H2O solution (REXCU-S) against Aedes aegypti, Anopheles quadrimaculatus, and Culex quinquefasciatus at 24, 48, and $72 \mathrm{~h}$ after exposure in laboratory and semi-field conditions.

\begin{tabular}{|c|c|c|c|c|c|c|}
\hline \multirow[b]{3}{*}{ Time duration (Hour) } & \multicolumn{6}{|c|}{ LC50 (ppm) of CuSO4.5H2O } \\
\hline & \multicolumn{2}{|c|}{ Ae. aegypti } & \multicolumn{2}{|c|}{ An. quadrimaculatus } & \multicolumn{2}{|c|}{ Cx. quinquefasciatus } \\
\hline & Lab. & Semi-field & Lab. & Semi-field & Lab. & Semi-field \\
\hline 24 & 13 & 5 & 11 & 6.5 & 14.5 & 4.5 \\
\hline 48 & 7 & 3.5 & 7.5 & 5 & 7 & 3 \\
\hline 72 & 5.5 & 3 & 2.25 & 1.5 & 2 & 1.5 \\
\hline
\end{tabular}

$\mathrm{LC}_{50}$ : Lethal concentration to kill $50 \%$ of the exposed larvae.

the larval midgut. However, further experiments may be needed to validate this.

Based on the $\mathrm{LC}_{50}$ values obtained from the laboratory evaluation, the order of susceptibleness among the larvae was as follows: Cx. quinquefasciatus $(2 \mathrm{ppm})>A n$. quadrimaculatus (2.25 ppm) > Ae. aegypti (5.5 ppm) after $72 \mathrm{~h}$. This result is in accordance with a study reported by Reza et. al. (2014), that at 3.3 ppm concentration of copper solution, $C x$. pipiens was more susceptible than An. stephensi and Ae. albopictus.

Based on the $\mathrm{LC}_{50}$ values obtained from the semi-field evaluation, the order of susceptibleness among the larvae was as follows: Cx. quinqufasciatus $(1.5 \mathrm{ppm})=A n$. quadrimaculatus (1.5 ppm) > Ae. aegypti (3 ppm) at $72 \mathrm{~h}$. Interestingly the order of susceptibleness among the mosquito larvae was the same as our laboratory test which was also supported by Reza et al. 2014.

In monitoring mortality, the semi-field results showed maximum larval mortality within earlier exposure time of 24 and 48 $\mathrm{h}$ while in the laboratory it was prolonged up to $72 \mathrm{~h}$. Besides, the observed $\mathrm{LC}_{50}$ values in semi-field conditions were comparatively lower than the laboratory conditions at any time period of exposure during experiment. The semi-field results might be attributed to different environmental factors like light, heat, etc. hence causing more larvicidal effect. Therefore, it can be said that $\mathrm{CuSO}_{4}$ solution is more toxic to mosquito larvae in semi-field conditions, compared to laboratory conditions.

It is summed up that the tested $\mathrm{CuSO}_{4} \cdot 5 \mathrm{H}_{2} \mathrm{O}$ have larvicidal activity against the mosquito larvae, especially on $C x$. que- faciatus and An. quadrimaculatus. This easy, safe, and low-cost alternative larvicide may be recommended for mosquito larval control. Continuous use of insecticide for controlling mosquitos and their larvae can enhance the resistance population. Therefore, a low concentration of $\mathrm{CuSO}_{4} \cdot 5 \mathrm{H}_{2} \mathrm{O}$ can be used as an alternative along with other chemical or biological insecticides for which problems have been reported with toxicities and resistances (Tetreau et al., 2012). This $\mathrm{CuSO}_{4} \cdot 5 \mathrm{H}_{2} \mathrm{O}$ solution may be directly used at the breeding sites of mosquitoes in stagnant water and in localized conditions. Thus, the findings of this study have demonstrated that the mortality of larvae by $\mathrm{CuSO}_{4} \cdot 5 \mathrm{H}_{2} \mathrm{O}$ is worth for further studies in open water bodies. Although several environmental issues are associated with copper, the careful utilization and strict control of low concentrations and limited usage will avoid contamination in the environment.

\section{ACKNOWLEDGMENT}

The authors would like to acknowledge to M.K. Gaines, R. Weaver, V. Aryaprema and other AMCD employees for their partial participation in this research study. The authors also extend their sincere appreciation to $\mathrm{J}$. Davidson, DNW Global, LLC, USA for supporting this research work.

\section{REFERENCES CITED}

Abbott WS.1925. A method of computing the effectiveness of an insecticide. JEcon Entomol 18: 256-257.

Arivoli S, Tennyson S, Martin JJ. 2011. Larvicidal efficacy of Vernonia cinerea (L.) (Asteraceae) leaf extracts 
against the filarial vector Culex quinquefasciatus Say (Diptera: Culicidae). J Biopest 4: 37-42

Beaty BJ, Mackie RS, Mattingly KS, Carlson JO, RaymsKeller A. 2002. The midgut epithelium of aquatic arthropods: a critical target organ in environmental toxicology. Environ Health Perspectives, 110 (suppl 6), 911-914.

Biagi M, Giachetti D, Miraldi E, Figura N. 2014. New nonalcoholic formulation for hand disinfection. $J$ Chemother, 26: 86-91

Finney DJ 1971. Probit Analysis: A Statistical Treatment of the Sigmoid Response Curves. $3^{\text {rd }}$ ed. Cambridge, UK: Cambridge University Press.

Hodson PV, Borgmann U, Shear H. 1979. Toxicity of copper to aquatic biota. In: Copper in the environment Part II: Health effects (Ed. J.O. Nriagu). John Wiley and Sons, New York. pp. 307-372.

Kirici M, Turk C, Caglayan C, Kirici M. 2017. Toxic effects of copper sulphate pentahydrate on antioxidant enzyme activities and lipid peroxidation of freshwater fish Capoeta umbla (Heckel, 1843) tissues. Applied Ecol Environ Res, 15(3), pp.1685-1696.

Kosalwat P, Knight AW.1987. Chronic toxicity of copper to a partial life cycle of the midge, Chironomus decorus. Arch Environ Contam Toxicol, 16, 283-290.

Langat KB, Siele DK, Wainaina C, Wandawiro CM, Ondicho J, Tonui WK, Anjili C, Irei L N, Mutai CK. 2012. Larvicidal effect of Mundulea sericea (Leguminosaea) plant extract against Aedes aegypti (L.) (Diptera: Culicidae). AfrJ Pharmacol Ther 1: 106- 109.

Lasiene K, Straukas D, Vitkus A, Juodziukyniene N. 2016. The influence of copper sulphate pentahydrate $(\mathrm{CuSO} 4.5 \mathrm{H} 2 \mathrm{O})$ on the embryo development in the guppies (Poecilia reticulata). Italian J Animal Sci, 15: 529-535.

Majumdar TN, Gupta A. 2012. Acute and chronic toxicity of copper on aquatic insect Chironomus ramosus from Assam, India. JEnviron Biol, 33(1), p.139.
Ndakidemi B, Mtei K, Ndakidemi PA. 2016. Impacts of synthetic and botanical pesticides on beneficial insects. Agric Sci 7: 364- 372.

Nebeker AV, Cairns MA, Wise CM. 1984. Relative sensitivity of Chironomus tentans life stages to copper. Environ Contam Toxicol., 3, 151-158.

Raveen R, Kamakshi KT, Deepa M, Arivoli S, Tennyson, S. 2014. Larvicidal activity of Nerium oleander L. (Apocynaceae) flower extracts against Culex quinquefasciatus Say (Diptera: Culicidae). Int J Mosq Res 1: 38-42.

Remia KM, Logaswamy S. 2010. Larvicidal efficacy of leaf extract of two botanicals against the mosquito vector Aedes aegypti (Diptera: Culicidae). J Nat Prod Resour 1: 208-212.

Reza M, Yamamoto DS, Matsuoka H. 2012. Low-concentration copper solution jeopardizes larval movement and ability to survive predation: New insight into malaria eradication via vector control. Med Entomol Zool, 63(3), 217-222.

Reza M, Yamamoto DS, Matsuoka H. 2014. Larvicidal and ovipositional preference test of copper solution for mosquitoes. Med Entomol Zool, 65(3), 147-150.

Tetreau G, Stalinski R, Kersusan D, Veyrenc S, David JP, Reynaud S, Després L. 2012. Decreased toxicity of Bacillus thuringiensis subsp. israelensis to mosquito larvae after contact with leaf litter. Appl Environ Microbiol, 78(15), 5189-5195.

Warrin E, Vedamanikam VJ, Shazilli NAM. 2009. Toxicity of three forms of copper to the Chironomus tentans in both the aquatic and sediment media. Toxicol Environ Chem, 91, 297-304.

WHO 2009. Guidelines for efficacy testing. Geneva, Switzerland, World Health Organization. Retrieved from https://www.who.int/neglected_diseases/vector_ecology/mosquito-borne-diseases /en/

WHO 2005. Guidelines for Laboratory and Field Testing of Mosquito Larvicides. Geneva, Switzerland: World Health Organization. 